\title{
The structural stability of protein antigens adsorbed by aluminium hydroxide in comparison to the antigens in solutions
}

\author{
Yiwu Zheng a,b ${ }^{\text {, Xuxin Lai }}{ }^{\text {a,b }}$, Henrik Ipsen ${ }^{\text {a }}$, Jørgen Nedergaard Larsen ${ }^{\text {a }}$, \\ Henning Løwenstein ${ }^{\mathrm{a}}$, Ib Søndergaard ${ }^{\mathrm{b}}$ and Susanne Jacobsen ${ }^{\mathrm{b}, *}$ \\ ${ }^{\text {a } A L K-A B E L L O ~ A / S, ~ H \phi r s h o l m, ~ D e n m a r k ~}$ \\ ${ }^{\mathrm{b}}$ Enzyme and Protein Chemistry, BioCentrum-DTU, Technical University of Denmark, Kgs. Lyngby, \\ Denmark
}

\begin{abstract}
It is believed that antigens should be adsorbed onto adjuvants in vaccines. The adsorption-modified structure of antigens is important to understand the mechanism of adjuvants and vaccine immunogenicity. The structural stability of antigens is of major importance. The changes in structure can be induced by degradation and/or increase of storage temperature. In this study the structural stability of two model antigens, bovine serum albumin (BSA) and $\beta$-lactoglobulin (BLG) were compared when they were adsorbed onto aluminium hydroxide and when they were in solutions using Fourier transform infrared attenuated total reflection (FTIR-ATR) spectroscopy. The structural stability of these two proteins was studied at different temperature and during storages. The present results showed that the structure of antigens can be stabilized by adsorption onto aluminium hydroxide. Non-adsorbed protein antigens present in vaccines may facilitate the degradation of the vaccine.
\end{abstract}

Keywords: Structural stability, FTIR-ATR, antigens, aluminium

\author{
Abbreviations \\ BSA, Bovine serum albumin; \\ BLG, $\beta$-Lactoglobulin; \\ FTIR, Fourier transform infrared spectroscopy; \\ ATR, Attenuated total reflection; \\ ADT, Accelerated degradation test.
}

\section{Introduction}

Aluminium-containing adjuvants are used in vaccines to adsorb antigens and enhance the immune response upon injection. Although the mechanism by which aluminium-containing adjuvants potentiate the immune response is not fully understood, it is generally accepted that the antigens should be adsorbed onto adjuvants [1]. The World Health Organization recommends that at least $80 \%$ of tetanus and

\footnotetext{
*Corresponding author: Susanne Jacobsen, Enzyme and Protein Chemistry, BioCentrum-DTU, Technical University of Denmark, Søltofts Plads, Building 224, 2800 Kgs. Lyngby, Denmark. Tel.: +45 4525 2741; Fax: +45 4588 6307; E-mail: sja@biocentrum.dtu.dk.
} 
diphtheria toxoids should be adsorbed onto aluminium-containing adjuvants [2]. Therefore, vaccines are produced by selecting adjuvants, $\mathrm{pH}$, buffer and/or ionic strength to achieve maximum adsorption of the antigens [1]. Previous studies [3,4] showed conflicting results regarding to the secondary structure when antigens were adsorbed onto aluminium hydroxide adjuvants. Jones et al. [3] demonstrated by FTIRATR spectroscopy that protein changed its secondary structure due to adsorption and that this structural change was one of the mechanisms by which aluminium adjuvants enhances the immune response of allergens. On other hand, Dong and his co-worker [4] showed by using the same technique that no protein structural change occurred.

Therefore, further investigations of secondary structures of antigens when adsorbed to aluminium hydroxide are needed in order to elucidate, if modification of protein structure occurs. Stability of adsorption-modified protein structure is of major importance, since modifications may induce degradation of the antigens during storage. Antigen degradation could potentially pose risk to patients. The term stability, when it relates to proteins, is often used in a variety of ways, including chemical and/or physical degradation [5]. In the present study we are primarily concerned with the secondary structure of proteins. Two model antigens bound to adjuvant were investigated during heating and storage in comparison to the antigens in solutions using FTIR-ATR spectroscopy. For the storage experiments, apart from normal storage temperature, i.e. $4^{\circ} \mathrm{C}$, an accelerated degradation test (ADT) was also employed, which subjected the samples to an elevated temperature, i.e. $37^{\circ} \mathrm{C}$, at which denaturation should occur more rapidly than at normal temperature. It is well known that some vaccines are temperature sensitive [6]. Both high and low (freezing) temperatures can cause inactivation of vaccines. In this work, structural stability of the model antigens was in addition investigated at different heating temperatures, since temperature alterations are an important problem during the transportation and storage of vaccines, especially in developing countries where the quality of the 'cold chain' is not always optimal [7].

\section{Materials and methods}

\subsection{Materials}

Clinical reagent grade bovine serum albumin (BSA, reference L84960) and $\beta$-lactoglobulin (BLG, reference L3908) were purchased from ICN biomedical Inc and Sigma, respectively. Both proteins were used directly without further purification. Aluminium hydroxide was purchased from Superfos Biosector $\mathrm{A} / \mathrm{S}$. A stock aluminium hydroxide was prepared by adjusting $\mathrm{pH}$ to 8.0 by the addition of $1 \mathrm{M} \mathrm{NaOH}$ before use. All other chemicals were analytical grade and obtained from commercial sources without further treatment.

\subsection{Sample preparation}

A stock protein solution $(20 \mathrm{mg} / \mathrm{ml})$ was prepared by dissolving protein in Milli-Q water. Model vaccines were prepared by mixing the appropriate amount of protein stock solution and aluminium hydroxide with end-over-end rotation for $30 \mathrm{~min}$ to obtain the maximum protein adsorption. The final calculated aluminium concentration was $3.4 \mathrm{mg} / \mathrm{ml}$ and the final protein concentrations $4.0 \mathrm{mg} / \mathrm{ml}$. Protein water solutions were prepared by diluting the stock solution to $4 \mathrm{mg} / \mathrm{ml}$ using Milli-Q water. Blank samples containing $3.4 \mathrm{mg} / \mathrm{ml}$ aluminium hydroxide without proteins were prepared by diluting the stock aluminium adjuvant using Milli-Q water. 


\subsection{FTIR-ATR measurement}

Spectra were collected using a FTIR spectrometer (PerkinElmer Spectrum One), which was mounted with a three bounces ZnSe ATR crystal (PerkinElmer). In the storage analysis, samples were stored at $4^{\circ} \mathrm{C}$ or $37^{\circ} \mathrm{C}$ between measurements. All samples were measured at room temperature. In the heating analysis experiments, the samples were divided into different vials and were heated at different temperatures $\left(25,37,50,60,70,80,90^{\circ} \mathrm{C}\right)$ for $30 \mathrm{~min}$, respectively; and reached to room temperature before FTIR measurement.

Total $8 \mu \mathrm{l}$ sample was deposited onto the ATR crystal and evaporated the solvent to make a film. The calculated amount of aluminium hydroxide for each film was $27.2 \mu \mathrm{g}$; and the calculated amount of protein was $32 \mu \mathrm{g}$. Spectra were directly recorded on the film by co-adding 128 scans with a resolution of $4 \mathrm{~cm}^{-1}$ at a scan speed $0.2 \mathrm{~cm} / \mathrm{s}$. Control spectra were recorded by measuring the blank samples which contained the same components except protein under the same experimental conditions. All samples were analyzed at least in duplicate.

\subsection{Data analysis}

All FTIR spectra were analyzed using the The Unscrambler v. 9.2 software (Camo process AS, Oslo, Norway). Replicate spectra of the same sample were averaged first. For the adsorbed proteins, the spectra of a corresponding blank sample were subtracted from the spectra of the adsorbed proteins. A flat baseline from 1900 to $1740 \mathrm{~cm}^{-1}$ was obtained for each spectrum after subtraction. A 23-point SavitskyGolay smoothing function was applied to each spectrum from $1800 \mathrm{~cm}^{-1}$ to $1200 \mathrm{~cm}^{-1}$. The second derivative spectra were calculated using an 11-point Savitsky-Golay function from 1750 to $1220 \mathrm{~cm}^{-1}$. The inverted second derivative spectra were obtained by multiplying by -1 for convenient interpretation. Finally, the spectra were baseline corrected and mean normalized.

\section{Results and discussion}

\subsection{Structural stability of protein antigens at different temperatures}

FTIR-ATR spectroscopy was applied to monitor the secondary structure of the model antigens in solution as well as adsorbed onto aluminium hydroxide as a function of temperature. The potential changes of the secondary structure were detected in the amide I $\left(1700-1600 \mathrm{~cm}^{-1}\right)$ and amide II $(1600$ $1500 \mathrm{~cm}^{-1}$ ) regions of the inverted secondary derivative spectra.

For BSA adsorbed by aluminium hydroxide, the distinguishable spectral changes occurred at or above $70^{\circ} \mathrm{C}$ (see Fig. 1). It showed that the $\alpha$-helix band around $1653 \mathrm{~cm}^{-1}$ decreased along with an increase in $\beta$-sheet around $1636 \mathrm{~cm}^{-1}$. Another spectral difference in the amide I region observed was the intensity of the band at high wavenumber $1693 \mathrm{~cm}^{-1}$. This band increased as a function of temperature, especially above $70^{\circ} \mathrm{C}$. In the amide II region, the intensity of bands around $1549 \mathrm{~cm}^{-1}$ and $1533 \mathrm{~cm}^{-1}$ decreased when the temperature increased. However, compared to the spectra of BSA in solution shown in Fig. 2, the above mentioned heat-induced spectral changes were less pronounced. BSA in solution showed significantly low thermal stability. A band resulting from intermolecular aggregation was induced around 1626 to $1622 \mathrm{~cm}^{-1}$, even at very low temperature. This band increased as a result of increasing temperature. Two other bands increased around $1695 \mathrm{~cm}^{-1}$ and $1680 \mathrm{~cm}^{-1}$ when elevated temperature. These three bands are related to intermolecular anti-parallel $\beta$-sheet formation [8-10]. 


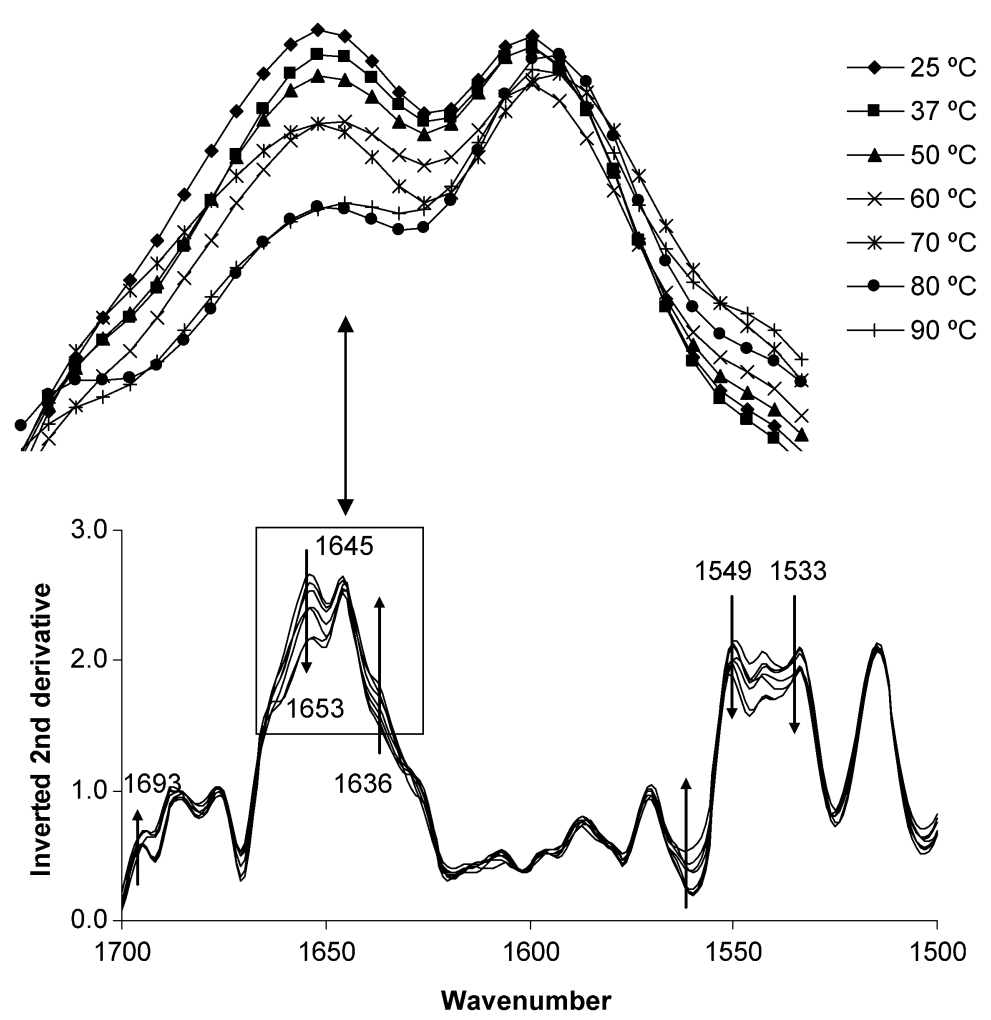

Fig. 1. Inverted 2nd derivative spectra of adsorbed BSA at different temperatures in amide I and amide II regions. BSA was adsorbed to aluminium hydroxide and incubated for $30 \mathrm{~min}$ before heating at different temperatures for $30 \mathrm{~min}$. The spectra were collected at room temperature. The directions of arrows show the shifts in spectra of samples at increasing temperatures.

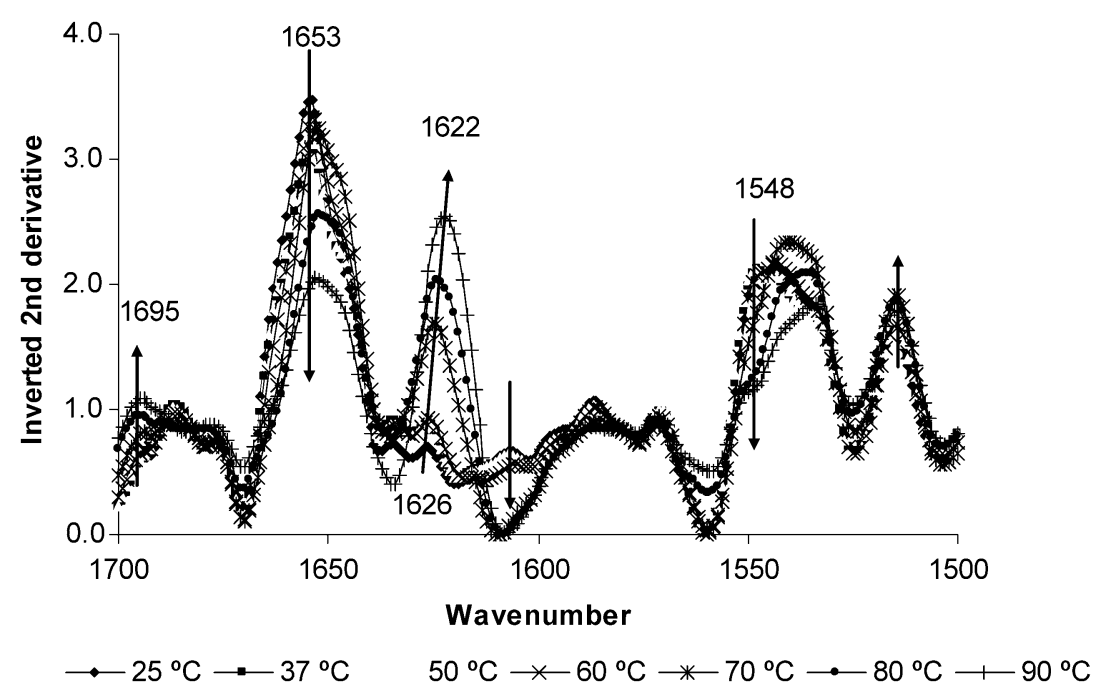

Fig. 2. Inverted 2nd derivative spectra of BSA solution at different temperatures in amide I and amide II regions. BSA solution was heated at different temperatures for $30 \mathrm{~min}$, measured at room temperature. The directions of arrows show the shifts in spectra of samples at increasing temperatures. 


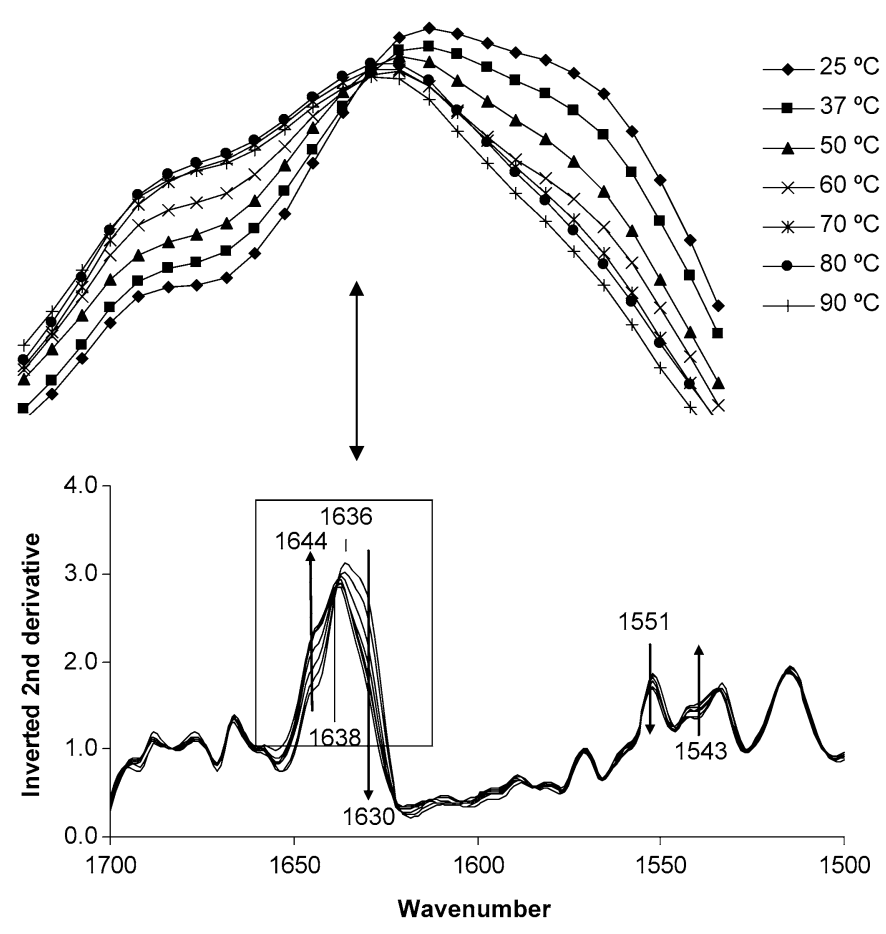

Fig. 3. Inverted 2nd derivative spectra of adsorbed BLG at different temperatures in amide I and amide II regions. BLG was adsorbed to aluminium hydroxide and incubated for $30 \mathrm{~min}$ before heated at different temperatures for $30 \mathrm{~min}$. The spectra were collected at room temperature. The directions of arrows show the shifts in spectra of samples at increasing temperatures.

These three aggregation-induced bands were also observed in other heat-denatured protein aggregates [11-13]. In the amide I region, the main $\alpha$-helix band at $1653 \mathrm{~cm}^{-1}$ shifted to $1652 \mathrm{~cm}^{-1}$ and the intensity decreased dramatically with increasing temperature. In other words, BSA in solution loses $\alpha$-helix structure and gains intermolecular $\beta$-sheet structure at high temperature.

The spectral difference between adsorbed BSA and BSA solution revealed that a modified structure was induced by adsorbing onto aluminium hydroxide, which agreed with previous study [3]. The less changeable spectra of adsorbed BSA indicated that adsorption-modified structure increased the protein thermal stability, which prevented intermolecular aggregating of protein during the heating process.

In the case of BLG, the spectra of adsorbed protein at different temperature were shown in Fig. 3, which were also significantly different from that of the protein in solution, seeing Fig. 4. The bands of adsorbed protein were located at wavenumbers that were not similar to the corresponding components of BLG in solution, which indicated that the secondary structure of adsorbed BLG changed as compared to native protein. As the temperature increased, the band of the adsorbed BLG around $1630 \mathrm{~cm}^{-1}$ lost intensity in Fig. 3, but there was a gain in the random structure as seen around $1644 \mathrm{~cm}^{-1}$. The main broad $\beta$-sheet band shifted from $1636 \mathrm{~cm}^{-1}$ to $1638 \mathrm{~cm}^{-1}$.

For BLG solution, the spectra at different temperatures were presented in Fig. 4 . The main $\beta$-sheet band appeared at $1628 \mathrm{~cm}^{-1}$ and the band broadened with increasing temperature. It can be seen that the band at $1694 \mathrm{~cm}^{-1}$ increased at high temperatures $\left(80,90^{\circ} \mathrm{C}\right)$, but no peak was induced around $1623 \mathrm{~cm}^{-1}$. The association state of BLG results from equilibrium between its monomeric and dimeric forms. Dimeric BLG is characterized by having two components around $1632 \mathrm{~cm}^{-1}$ and $1623 \mathrm{~cm}^{-1}$, while monomeric BLG reveals only one component near $1630 \mathrm{~cm}^{-1}$ [14]. Therefore, in the current ex- 


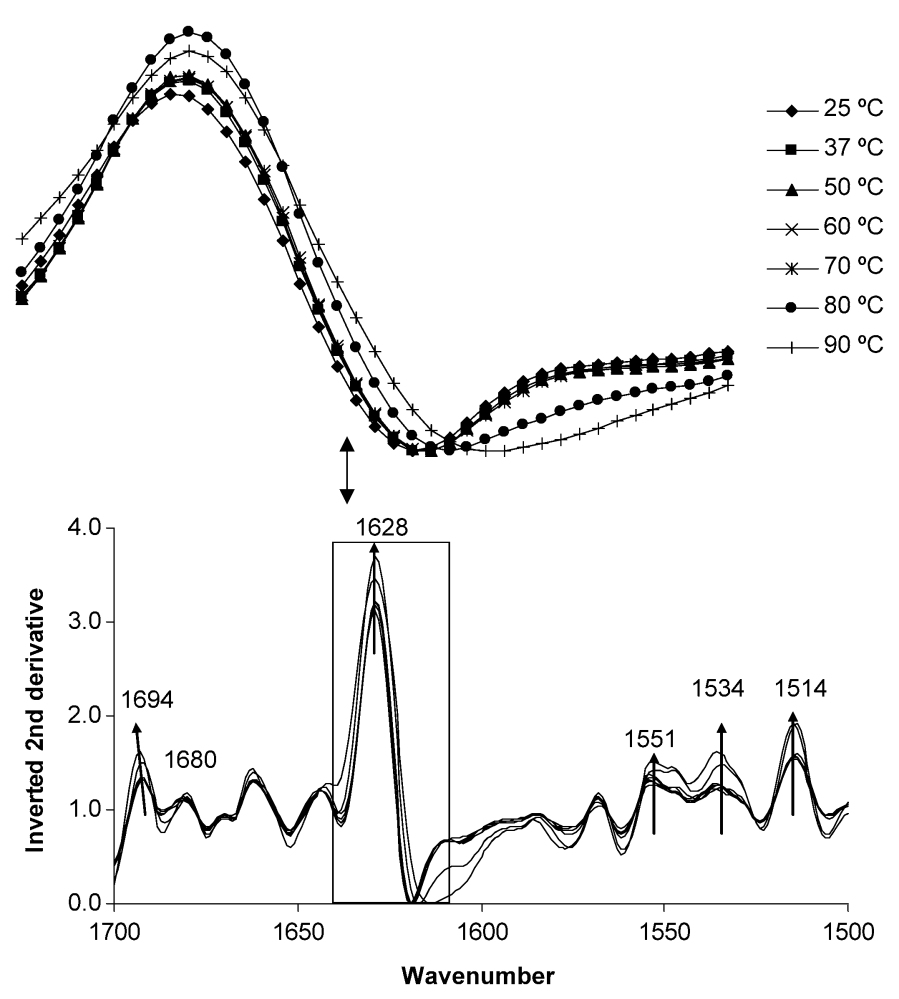

Fig. 4. Inverted 2nd derivative spectra of BLG solution at different temperature in amide I and amide II regions. BLG solution was heated at different temperatures for $30 \mathrm{~min}$ but measured at room temperature. The directions of arrows show the shifts in spectra of samples at increasing temperatures.

perimental conditions, BLG seemed to be primarily in the monomeric form. This probably resulted from low protein concentration $[15,16]$. Infrared spectra of BLG varied significantly in the low concentration range [17]. The spectra were characterized by one band between 1640 and $1623 \mathrm{~cm}^{-1}$ at low concentrations, whereas two bands around 1634 and $1623 \mathrm{~cm}^{-1}$ were present at high concentrations. High temperatures [17] and low ionic strength [18] may also result in the BLG spectrum having one FTIR band between 1640 and $1623 \mathrm{~cm}^{-1}$ instead of two bands around 1634 and $1623 \mathrm{~cm}^{-1}$.

A small band around $1680 \mathrm{~cm}^{-1}$ was induced for BLG solution at high temperature, i.e. 80 and $90^{\circ} \mathrm{C}$. It can also be attributed to the formation of intermolecular $\beta$-sheets that result from the self-aggregation of the proteins [19]. The intensity of this band was weak probably because the spectra were recorded at room temperature. The decreased temperature may facilitate refolding of the BLG structure. In amide I region the intensity decreased around $1610-1600 \mathrm{~cm}^{-1}$. It is usually not assigned to any secondary structural elements, which makes understanding the increasing intensity rather difficult. In the amide II region, the intensity of bands around 1551, 1534 and $1514 \mathrm{~cm}^{-1}$ increased significantly when elevated temperatures.

No intermolecular aggregation was observed for adsorbed protein at high temperature, i.e. above $70^{\circ} \mathrm{C}$, while protein in solution aggregated under similar conditions. The results suggested that the adsorption onto aluminium hydroxide can prevent intermolecular aggregation of the antigen when it was exposed to high temperature. However, the structure of adsorbed protein also changed slightly at low temperature, i.e. $37^{\circ} \mathrm{C}$. Jones and co-workers [3] demonstrated that the transition of aluminium hydroxide adsorbed BSA started at approximately $35^{\circ} \mathrm{C}$ using differential scanning calorimetry. This temperature was lower 
than the temperature which caused transition of BSA in solution. Thus, it was concluded that proteins adsorbed to aluminium-containing adjuvant show significantly reduced thermal stability compared to the protein in solution. However, they observed the temperatures at which the protein started to destabilize, and made no conclusion concerning the high temperature effects. The difference of the FTIR measurements in these two studies was that Jones et al. [3] measured the slurry after centrifugation compared to evaporated films which were analyzed in this work. Another difference is Jones et al. [3] measured the sample at the denaturing temperature in comparison to room temperature in this work. The buffer difference in vaccine preparation may also play an important role in the structural stability of BSA [20]. The thermal effect on the stability of absorbed BSA and BLG is not the same. This result agrees with the study of Jones et al. [3] showing that the stability of ovalbumin was less affected by adsorption than BSA.

\subsection{Structural stability during the storage at two temperatures}

The structural stability of adsorbed antigen is important especially when the vaccine is stored for long periods prior to use. It is well known that vaccines lose their potency during storage, especially at high temperature [21]. The mechanism by which vaccine loses potency is not clear. The structural stability may influence the immunogenicity of the vaccine. FTIR-ATR spectroscopy was applied here to monitor the structural changes of protein antigens during the storage in the amide I and the amide II region.

The alteration of the secondary structure of two model antigens during 4 months of storage was studied in this work. The second derivative FTIR spectra of adsorbed BSA which was stored both at $37^{\circ} \mathrm{C}$ and $4^{\circ} \mathrm{C}$ did not change much (see Fig. 5). Similar spectra indicated that the structure of BSA was
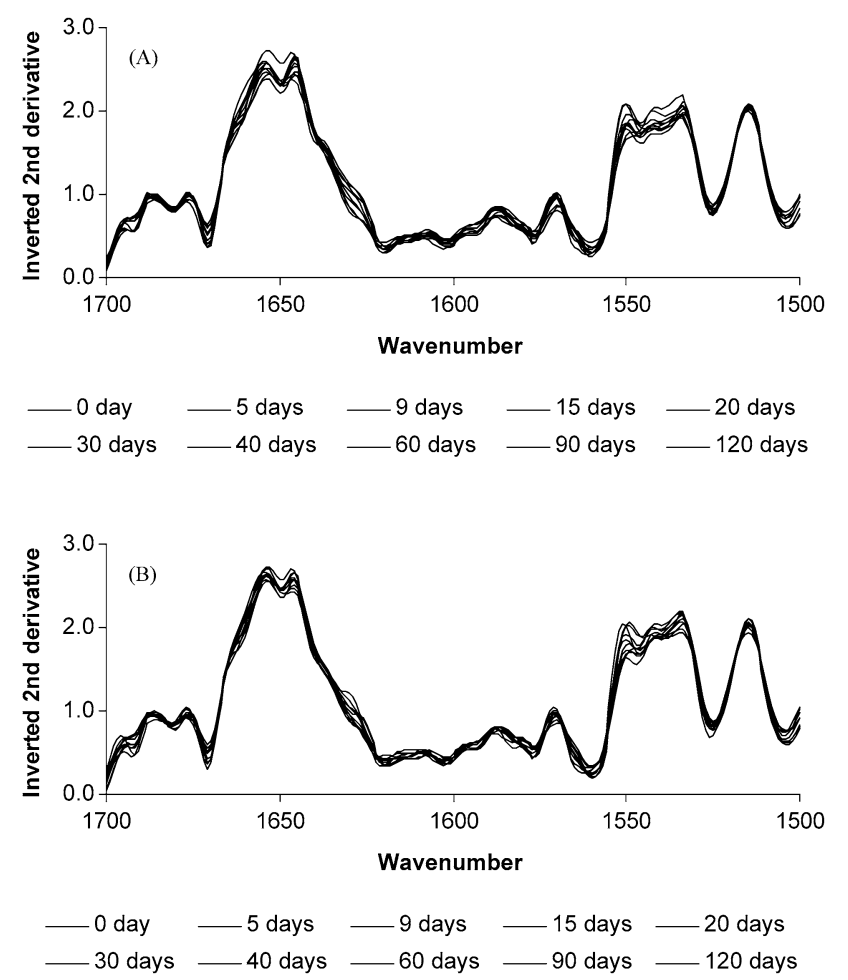

Fig. 5. Inverted 2nd derivative spectra of adsorbed BSA during 120 days storage in amide I and amide II regions. BSA was adsorbed to aluminium hydroxide and stored at $37^{\circ} \mathrm{C}(\mathrm{A})$ and $4^{\circ} \mathrm{C}(\mathrm{B})$ respectively. 


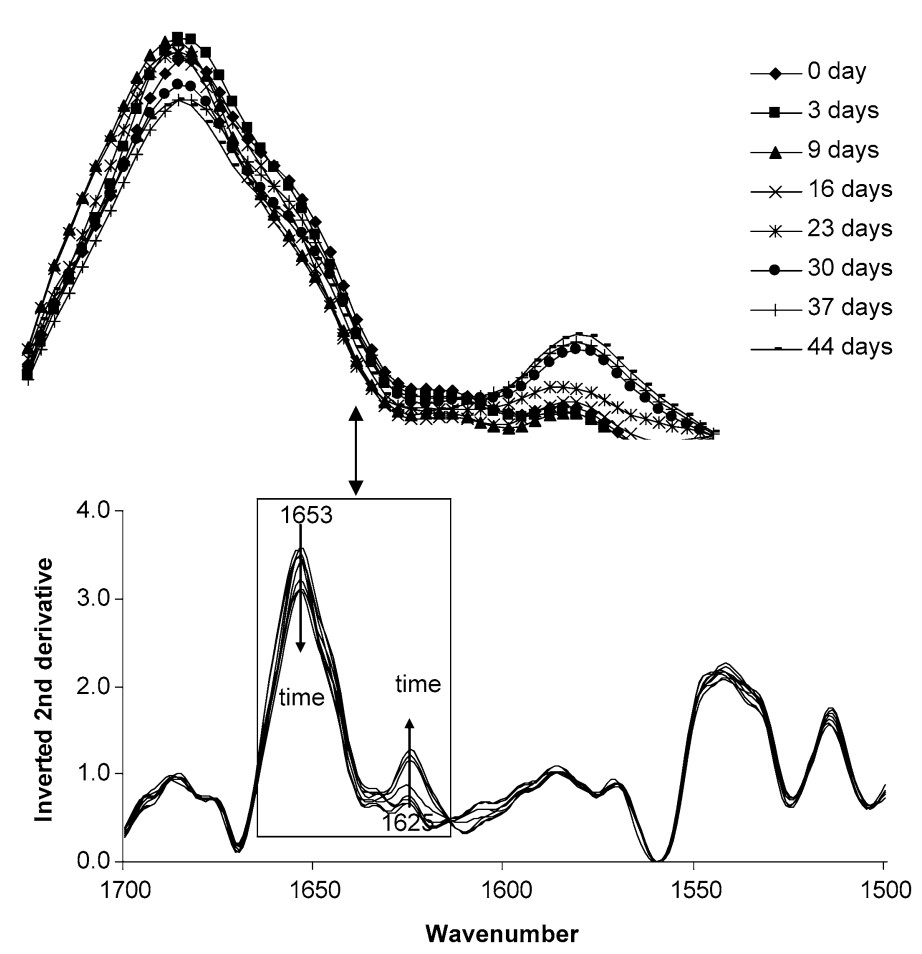

Fig. 6. Inverted 2nd derivative spectra of BSA solution after 44 days storage at $37^{\circ} \mathrm{C}$ in amide I and amide II regions.

stable, when adsorbed to aluminium hydroxide. Slight spectral differences did occur, but the changes were irregular and the spectral variability may be caused by experiment-to-experiment variation and inconsistent measurement of the temperature.

The stability of BSA in solution when stored at $37^{\circ} \mathrm{C}$ and $4{ }^{\circ} \mathrm{C}$ were also investigated. The secondary structure of BSA in solution changed dramatically in 44 days when stored at $37^{\circ} \mathrm{C}$ (Fig. 6) and white sedimentation was observed within 65 days. A new peak was induced at $1625 \mathrm{~cm}^{-1}$ after 16 days storage. The intensity of the peak increases as a function of time. The band is due to the intermolecular antiparallel $\beta$-sheet formation. On the other hand, the $\alpha$-helix band at $1653 \mathrm{~cm}^{-1}$ decreased with increasing storage time. Thus, for BSA in solution, $\alpha$-helix was reduced accompanied by an increase in anti-parallel $\beta$-sheet explained by intermolecular aggregation. BSA in solution was stable when it is stored at $4{ }^{\circ} \mathrm{C}$. The spectrum changed slightly after 65 days of storage (data not shown).

In the case of BLG, the secondary derivative FTIR spectra of adsorbed BLG stored at $37^{\circ} \mathrm{C}$ and $4{ }^{\circ} \mathrm{C}$ were given in Fig. 7 and Fig. 8, respectively. The $\beta$-sheet band around $1636 \mathrm{~cm}^{-1}$ shifted to higher wavenumbers, and the intensity decreased as a function of time. The change was more pronounced in the early stage of the storage, i.e. first three weeks. On the other hand, the bands from 1606 to $1587 \mathrm{~cm}^{-1}$ increased with storage. In the amide II region, bands around 1551 and $1534 \mathrm{~cm}^{-1}$ increased. The results agreed with another study [21], in which it demonstrated that adsorption of BLG to an oil-water interface lead to time-dependent changes in the protein structure. The dramatic changes of adsorbed BLG may result from free protein in the samples. BLG $(4 \mathrm{mg} / \mathrm{ml})$ cannot be totally adsorbed by $3.4 \mathrm{mg} / \mathrm{ml}$ aluminium hydroxide. Adsorbed BLG was released from aluminium hydroxide during storage, while the amount of adsorbed BSA remained constant (data not shown). Moreover, if $8 \mathrm{mg} / \mathrm{ml} \mathrm{BSA}$ was added to $3.4 \mathrm{mg} / \mathrm{ml}$ aluminium hydroxide it would give more non-adsorbed BSA in the system and the sam- 


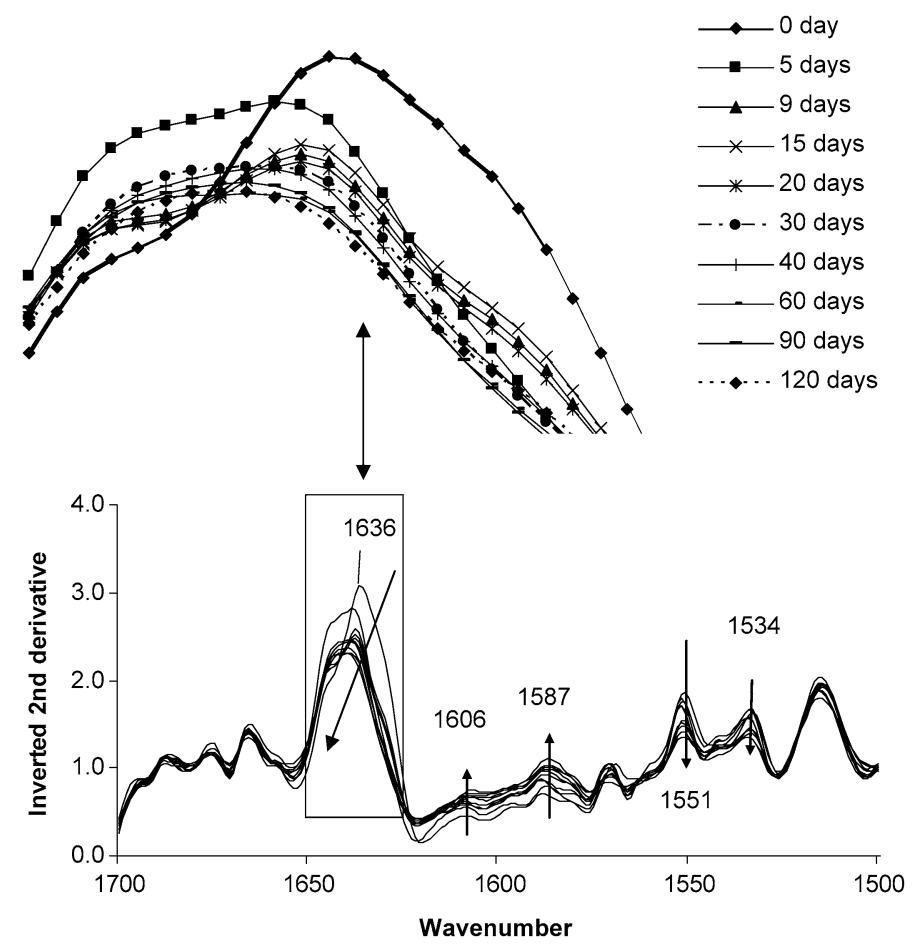

Fig. 7. Inverted 2nd derivative spectra of adsorbed BLG after 120 days storage at $37^{\circ} \mathrm{C}$ in amide I and amide II regions.

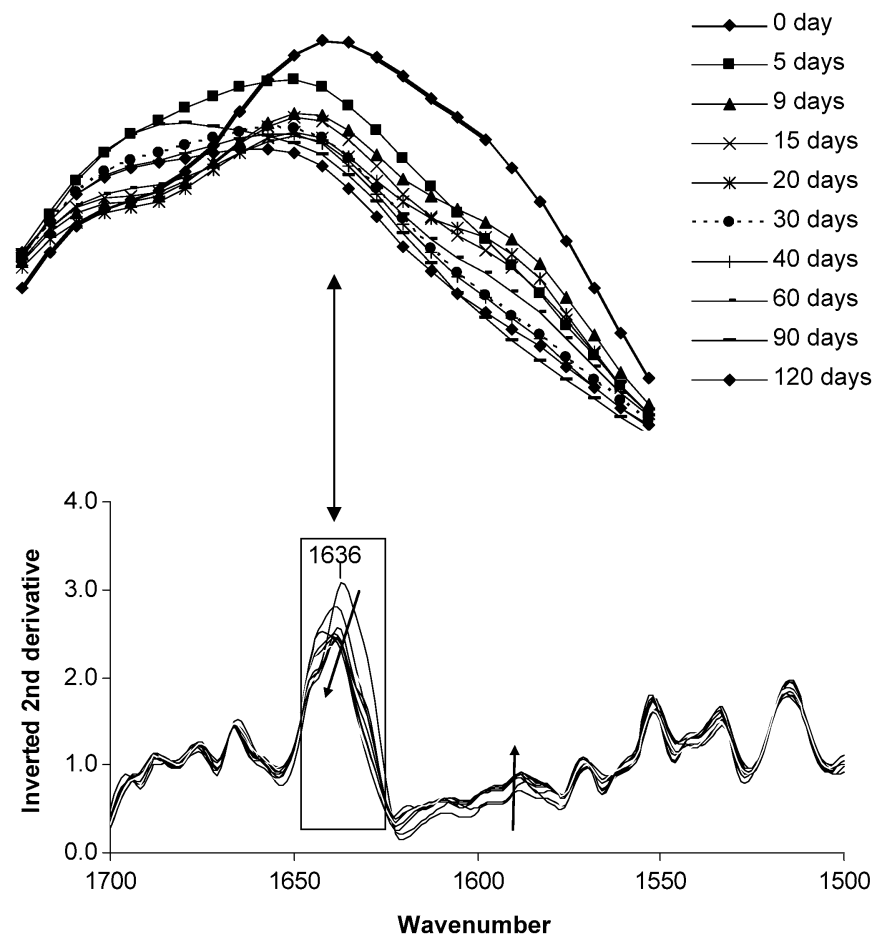

Fig. 8. Inverted 2 nd derivative spectra of adsorbed BLG after 120 days storage at $4{ }^{\circ} \mathrm{C}$ in amide I and amide II regions. 


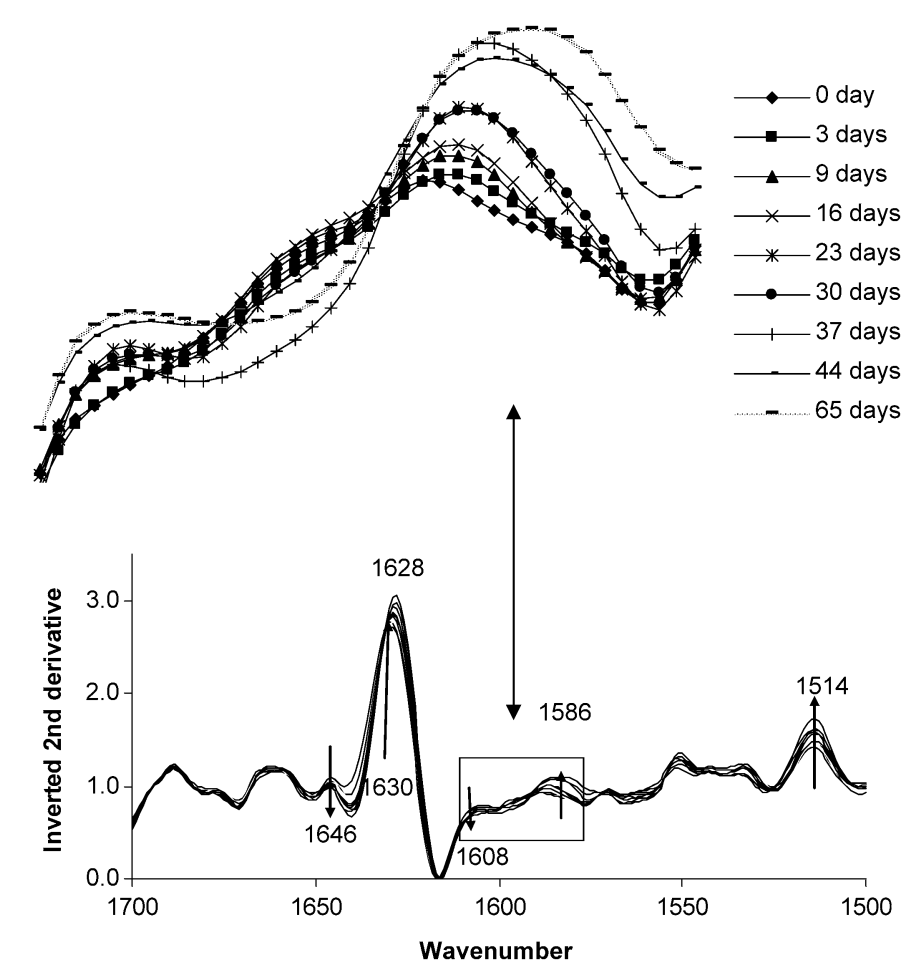

Fig. 9. Inverted 2nd derivative spectra of BLG solution after 65 days storage at $37^{\circ} \mathrm{C}$ in amide I and amide II regions.

ple aggregates rapidly. The data did not allow for an accurate estimation of structural analysis due to the aggregation after 4 weeks at $37^{\circ} \mathrm{C}$. Therefore, non-adsorbed antigens in vaccines may facilitate the deterioration of the vaccine. Furthermore, the alteration of $\mathrm{pH}$ from 7.6 to 7.0 during storage may also contribute a little to the structural change of adsorbed BLG.

For BLG in solution stored at $37^{\circ} \mathrm{C}$ and $4^{\circ} \mathrm{C}$, the FTIR spectra were shown in Figs 9 and 10, respectively. The $\beta$-sheet band at $1630 \mathrm{~cm}^{-1}$ increased and it shifted to lower wavenumber around $1628 \mathrm{~cm}^{-1}$ for BLG solution with increasing storage time at $37^{\circ} \mathrm{C}$. It indicated that the molecules of BLG aggregate due to intermolecular interaction. If BLG solution was stored at $4^{\circ} \mathrm{C}$, the $\beta$-sheet band at $1630 \mathrm{~cm}^{-1}$ lost intensity as function of storage time. However, a band around $1545 \mathrm{~cm}^{-1}$ increased, which can be described as random structure. In other words, BLG lost $\beta$-sheet but gained random structure when stored at low temperature. When BLG solution was stored at $37^{\circ} \mathrm{C}$, the variability of the spectra around $1586 \mathrm{~cm}^{-1}$ was evident. The intensity of this band increased as function of time.

\section{Conclusion}

This preliminary study showed that the structure of an antigen can be stabilized by adsorption to aluminium hydroxide during exposure to high temperature and/or during storage. The phenomenon is obvious for BSA when it is stored at $37^{\circ} \mathrm{C}$. In the case of BLG, due to the low protein concentration and non-adsorbed protein influence, it is not pronounced. Non-adsorbed protein antigens present in vaccines may facilitate the degradation of the vaccine. It requires further experiments to confirm this hypoth- 


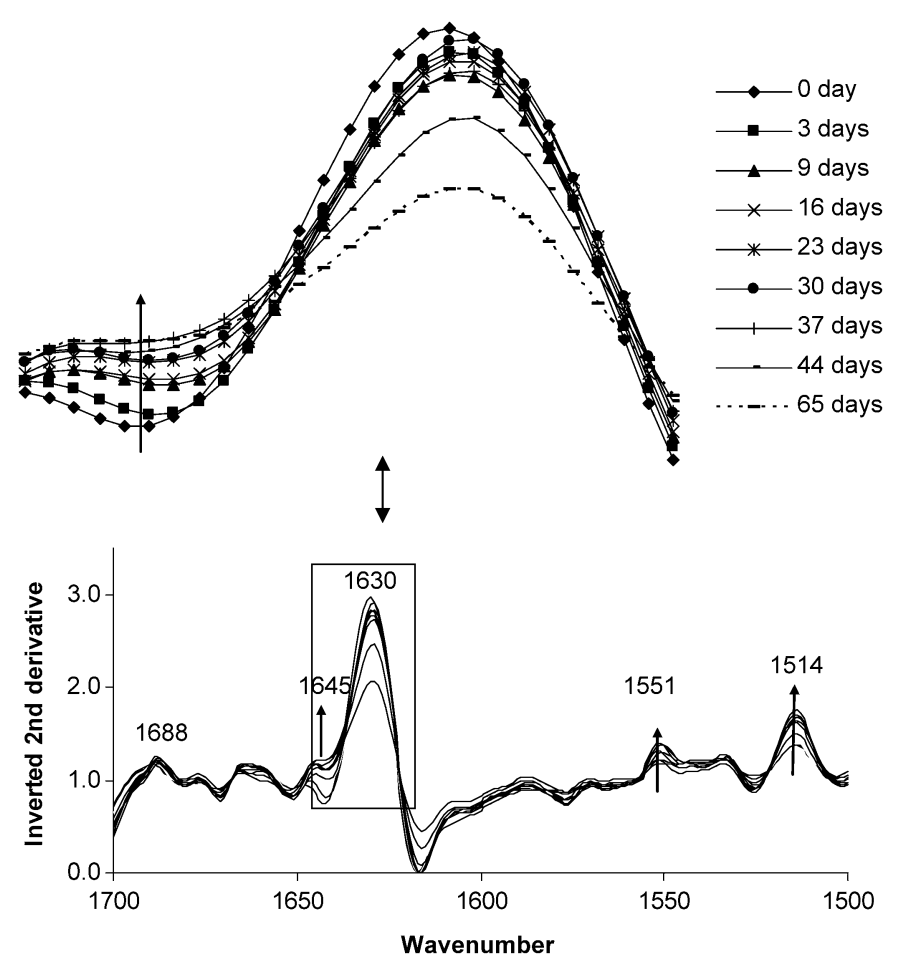

Fig. 10. Inverted 2nd derivative spectra of BLG solution after 65 days storage at $4^{\circ} \mathrm{C}$ in amide $\mathrm{I}$ and amide II regions.

esis. As expected, at elevated temperature, i.e. $37^{\circ} \mathrm{C}$, two proteins no matter adsorbed by aluminium hydroxide or not degrade more rapidly than at the normal storage temperature, $4^{\circ} \mathrm{C}$.

\section{Acknowledgements}

We gratefully acknowledge the financial support from the Ministry of Science, Technology and Innovation under its Industrial $\mathrm{PhD}$ initiative and from ALK-Abelló A/S.

\section{References}

[1] M.F. Chang, Y. Shi, S. L. Nail, H. HogenEsch, S.B. Adams, J.L. White and S.L. Hem, Degree of antigen adsorption in the vaccine or interstitial fluid and its effect on the antibody response in rabbits, Vaccine 19 (2001), 2884-2889.

[2] J.S. Jones, L.J. Peek, J. Power, A. Markham, B. Yazzie and C.R. Middaugh, Effects of adsorption to aluminium salt adjuvants on the structure and stability of model protein antigens, J. Biol. Chem. 280 (2005), 13406-13414.

[3] A. Dong, L.S. Jones, B.A. Kerwin and J.F. Carpenter, Secondary structures of proteins adsorbed onto aluminium hydroxide adjuvant: infrared spectroscopic analysis of proteins from low solution concentrations, Anal. Biochem. 351 (2006), 282289.

[4] M.C. Manning, K. Patel and R.T. Borchardt, Stability of protein pharmaceuticals, Pharm. Res. 6 (1989), 903-917.

[5] K.J. Frank, Monitoring temperature-sensitive vaccines and immunologic drugs, including anthrax vaccine, Am. J. HealthSyst. Pharm. 56 (1999), 2052-2055.

[6] F. Coenen, J.T. Tolboom and H.W. Frijlink, Stability of influenza sub-unit vaccine. Does a couple of days outside the refrigerator matter, Vaccine 24 (2006), 525-531.

[7] V. Militello, C. Casarino, A. Emanuele, A. Giostra, F. Pullara and M. Leone, Aggregation kinetics of bovine serum albumin studied by FTIR spectroscopy and light scattering, Biophys. Chem. 107 (2004), 175-187. 
[8] F. Meersman, L. Smeller and K. Heremans, Comparative Fourier transform infrared spectroscopy study of cold-, pressureand heat-induced unfolding and aggregation of myoglobin, Biophys. J. 82 (2002), 2635-2644.

[9] I.H.M. van Stokkum, H. Linsdell, J.M. Hadden, P.I. Haris, D. Chapman and M. Bloemenda, Temperature-induced changes in protein structures studied by Fourier transform infrared spectroscopy and global analysis, Biochemistry 34 (1995), $10508-10518$.

[10] C. Schladitz, E.P. Vieira, H. Hermel and H. Mohrwald, Amyloid- $\beta$-sheet formation at the air-water interface, Biophys. J. 77 (1999), 3305-3310.

[11] B.S. Kendrick, J.L. Cleland, X. Lam, T. Nguyen, T.W. Randolph, M.C. Manning and J.F. Carpenter, Aggregation of recombinant human interferon gamma: kinetics and structural transitions, J. Pharm. Sci. 87 (1998), 1069-1076.

[12] A. Dong, S.J. Prestrelski, S.D. Allison and J.F. Carpenter, Infrared spectroscopy studies of lyophilization- and temperatureinduced protein aggregation, J. Pharm. Sci. 84 (1995), 415-424.

[13] T. Lefevre and M. Subirade, Conformational rearrangement of $\beta$-lactoglobulin upon interaction with an anionic membrane, Biochim. Biophys. Acta 1549 (2001), 37-50.

[14] T. Lefevre and M. Subirade, Structural and interaction properties of $\beta$-lactoglobulin as studied by FTIR spectroscopy, Int. J. Food Sci. Technol. 34 (1999), 419-428.

[15] M.B. Czarnik, K. Murayama, Y. Wu and Y. Ozaki, Two-dimensional attenuated total reflection/infrared correlation spectroscopy of adsorption-induced and concentration-dependent spectral variations of $\beta$-lactoglobulin in aqueous solutions, J. Phys. Chem. 104 (2000), 7803-7811.

[16] T. Lefevre and M. Subirade, Interaction of $\beta$-lactoglobulin with phospholipids bilayers: a molecular level elucidation as revealed by infrared spectroscopy, Int. J. Biol. Macromol. 28 (2000), 59-67.

[17] P. Aymard, D. Durand and T. Nicolai, The effect of temperature and ionic strength on the dimerisation of $\beta$-lactoglobulin, Int. J. Biol. Macromol. 19 (1996), 213-221.

[18] A.H. Clark, D.H.P Saunderson and A. Suggett, Infrared and laser-Raman spectroscopic studies of thermally-induced globular protein gels, Int. J. Pept. Protein Res. 17 (1981), 353-364.

[19] H. Larsericsdotter, S. Oscarsson and J. Buijs, Structure, stability, and orientation of BSA adsorbed to silica, J. Colloid Interf. Sci. 289 (2005), 26-35.

[20] S.C. Arya and N. Agarwal, Efficacy of measles vaccine interlinked with potency and storage, Acta Trop. 90 (2004), 223225.

[21] Y. Fang and D.G. Dalgleish, Conformation of $\beta$-lactoglobulin studied by FTIR: effect of $\mathrm{pH}$, temperature, and adsorption to the oil-water interface, J. Colloid Interf. Sci. 196 (1997), 292-298. 


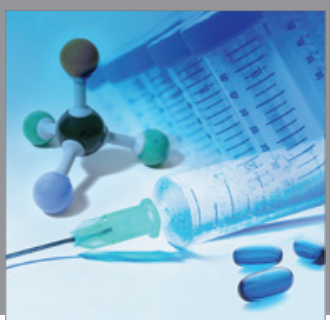

International Journal of

Medicinal Chemistry

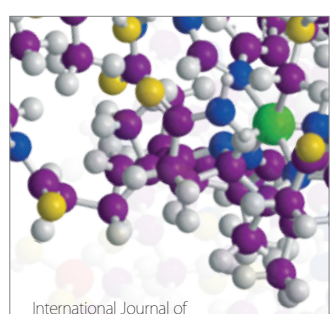

Carbohydrate Chemistry

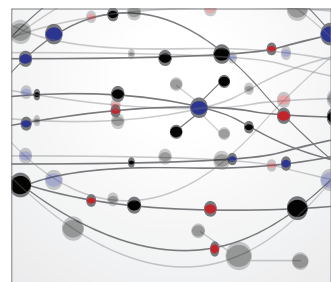

The Scientific World Journal
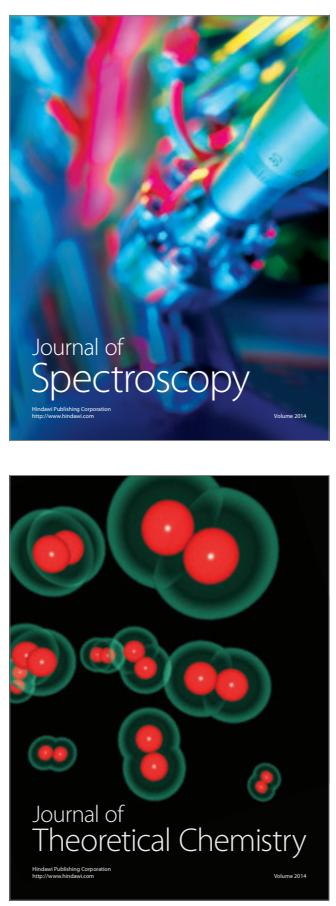
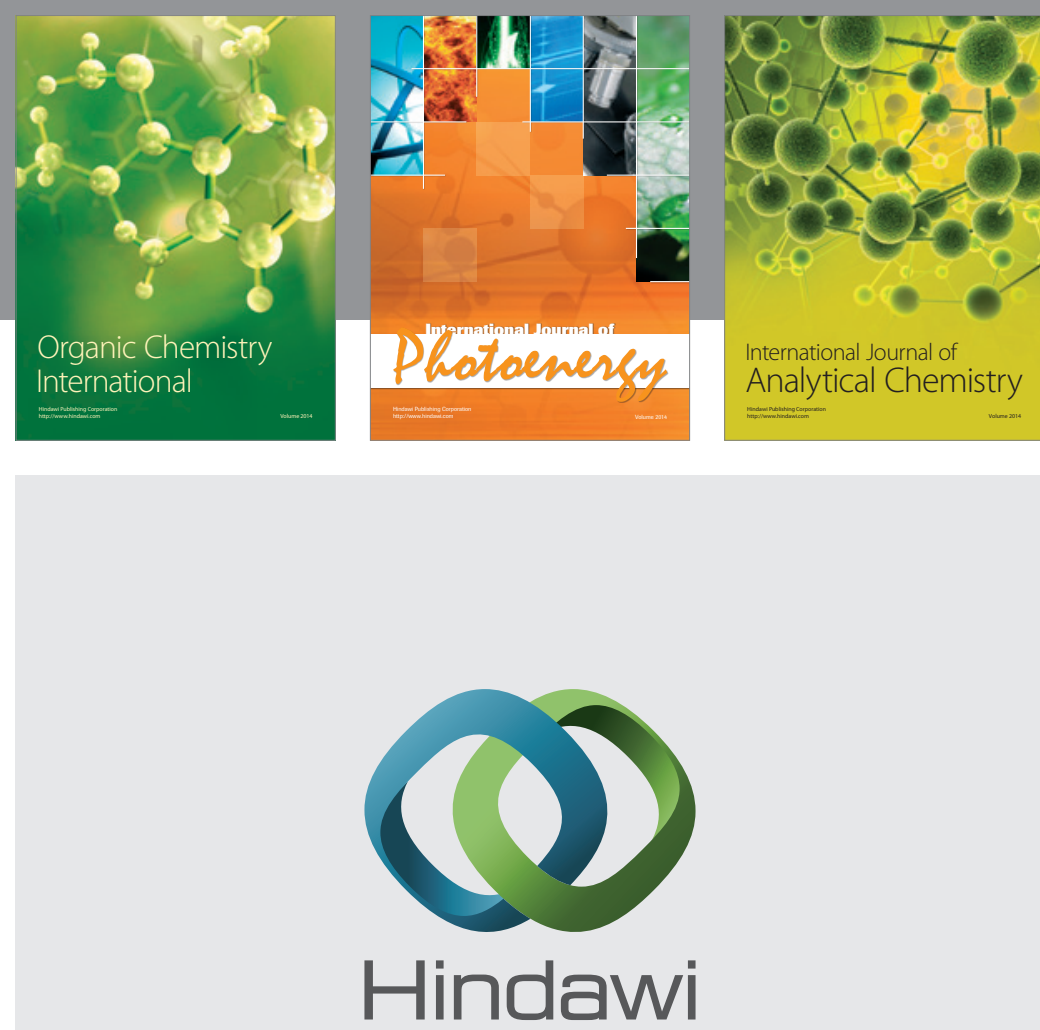

Submit your manuscripts at

http://www.hindawi.com
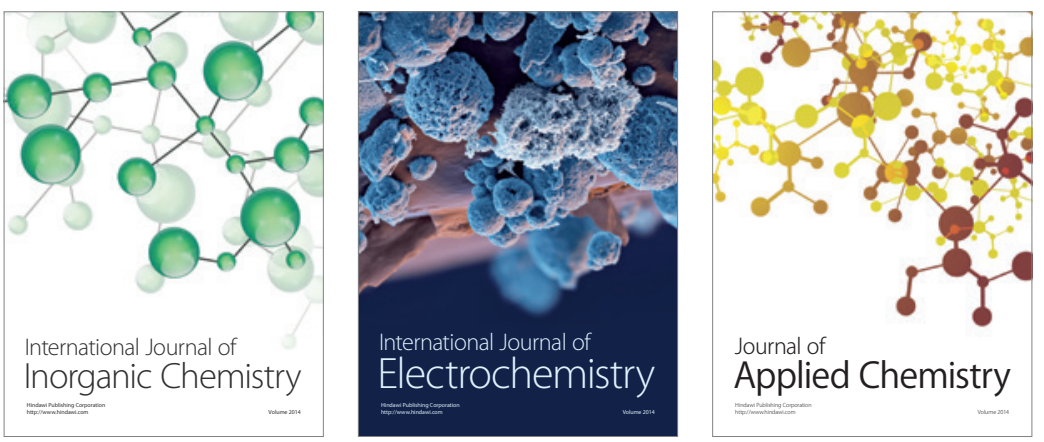

Journal of

Applied Chemistry
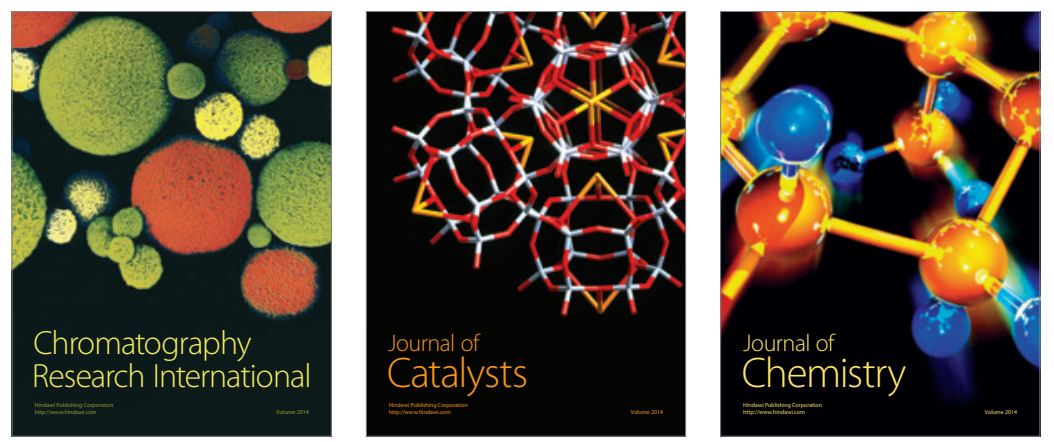
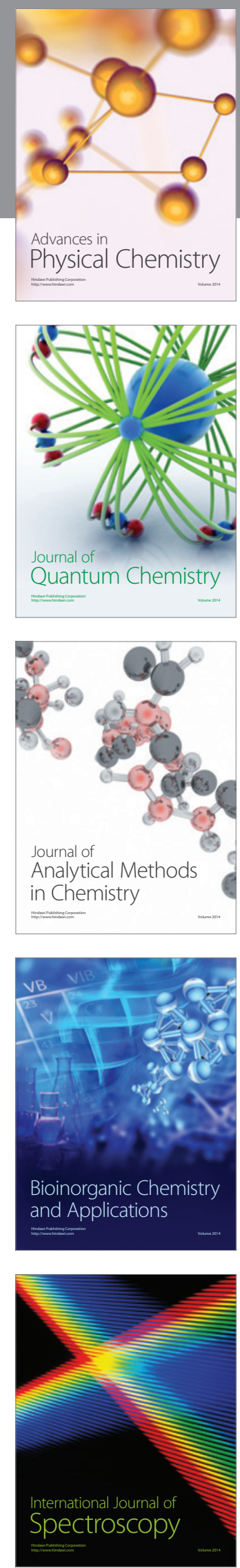